\title{
Correlation between CRP Level and Neutrophil Extracellular Traps in Malignancy Patients with Neutropenic Fever
}

\author{
Phey Liana ${ }^{1,2}$, Kemas M Yakub ${ }^{1}$, Eny Rahmawati ${ }^{1,2}$, Berliana Agustin ${ }^{3}$ \\ Department of Clinical Pathology, Faculty of Medicine, Universitas Sriwijaya, Palembang, Indonesia. E-mail: pheyliana@yahoo.com \\ ${ }^{2}$ Dr. Mohammad Hoesin Hospital Palembang, Indonesia \\ ${ }^{3}$ Faculty of Medicine, Universitas Sriwijaya, Palembang, Indonesia
}

\begin{abstract}
The mortality and morbidity rate of neutropenic fever is quite high. The source and severity of infection must be evaluated quickly in neutropenic patients. C-Reactive Protein (CRP) and Neutrophil Extracellular Traps (NETs) are known as markers for severeinfection. Besides, NETs also play a role in the development and metastasis of cancer but the mechanism is still unclear. C-reactive protein is a marker that is routinely used for infection. However, the correlation between CRP levels and NETs in malignant patients with neutropenia is unknown. Therefore this study was conducted to determine the correlation between CRP levels and NETs in malignant patients with neutropenia. This research was a cross-sectional observational study. The samples were malignant patients with neutropenia who were treated in the Pediatric Ward of Dr. Mohammad Hoesin Hospital, Palembang and met the inclusion and exclusion criteria. Sampling was done by consecutive sampling. C-reactive protein level and NETs weretested by immunoturbidimetry and ELISA methods. Data were analyzed with the Pearson test $(p<0.05)$. The mean of CRP and NETs level were $170.17 \pm 121.52 \mathrm{mg} / \mathrm{L}$ and $0.77 \pm 0.39 \mathrm{ng} / \mathrm{mL}$, respectively. The correlation test between CRP level and NETs in malignancy patients with neutropenic fever showed $r=0.228$ and $p=0.362$. The results showed no significant correlation between CRP level and NETs in malignant patients with neutropenic fever.
\end{abstract}

Keywords: Neutrophil extracellular traps, C-reactive protein, malignancy, neutropenic fever infection

\section{INTRODUCTION}

World Health Organization data in 2018 showed that 300,000 children per year were diagnosed with cancer. Other data from the Union for International Cancer Control (UICC) show that there are approximately 176,000 children diagnosed with cancer every year and most of them are from low and middle-income countries.

Infection is a major cause of morbidity and mortality in patients with malignancy. In pediatric malignancies, severe and prolonged neutropenia is associated with the use of intensive chemotherapy protocols, which cause infection. ${ }^{1}$ Neutropenia is the most frequent complication in patients receiving cytotoxic cancer therapy, which consists of $10-50 \%$ solid tumors and $>80 \%$ hematologic malignancies. Infection in neutropenic fever is divided into three groups, such as Microbiologically Documented Infection (MDI), Clinically Documented Infection (CDI), and Unexplained Fever (UF). ${ }^{2}$

Due to the high mortality and morbidity of neutropenic fever, measurement of CRP levels and Neutrophil Extracellular Traps (NETs) is needed as a marker for the severity of the infection. ${ }^{3}$ Neutrophil extracellular traps are derivatives released by neutrophils as fibers consisting of chromatin and neutrophil proteins that function to capture and kill bacteria. ${ }^{4,5}$ Citrullinated histone $\mathrm{H} 3$ (Cit H3) is one of the components involved in the formation of NETs through chromatin condensation. Citrullination histone $\mathrm{H} 3$ by Peptidylarginine Deaminase 4 (PAD4) occur through chromatin decondensation during "NETosis". 6

A study by Kim et al. showed a significant correlation between CRP levels and NETs in patients with coronary heart disease. ${ }^{7}$ Study by Zhu et al. in influenza patients showed that there was a correlation between CRP with cell-free DNA (cfDNA) level. ${ }^{8}$ However, the study by Kurz et al. showed different results that there was no correlation between CRP and NETs in small vessel vasculitis. Studies regarding the correlation between CRP and NETs levels in malignant patients with neutropenic fever are still very limited. Therefore, this study was performed to determine whether there is a correlation between CRP levels and NETs in malignant patients with neutropenic fever. 


\section{METHODS}

The study was an observational analytic study with a cross-sectional design and was performed from June to November 2019. The types of data used were primary and secondary data. Secondary data (patients characteristics) were taken from the results of research by Dr. Jayanti Mandasari Nasution. ${ }^{10}$ Characteristic data in this study were age, gender, nutritional status, length of fever, diagnosis, and infectioncategory. Nutritional status was determined by Body Mass Index (BMI) anthropometry based on 2000 Centers for Disease Control (CDC) growth charts. It consisted of 3 categories, such as for overweight $\left(85^{\text {th }}\right.$ percentile $B M I<95^{\text {th }}$ percentile), healthy weight (BMI between 5 percentile and 85 percentile), and underweight (BMI $<5^{\text {th }}$ percentile). Neutropenic fever was defined as a single oral temperature $38.3^{\circ} \mathrm{C}$ or $38.0^{\circ} \mathrm{C}$ for $\geq 1$ hour with an absolute neutrophil count $<500$ cells $/ \mathrm{mm}^{3}$ or $<1000$ cells $/ \mathrm{mm}^{3}$ and expected to decrease to $<500$ cells $/ \mathrm{mm}^{3}$ within the following 48 hours. Types of infections in neutropenic fever were classified into three groups as follows: Clinically Documented Infection (CDI), defined as clinically identified infections (e.g. pneumonia, cellulitis, or skin infection) without evidence of any microbiological pathogens; Microbiologically Documented Infection (MDI), defined as clinically identified infection proven by positive blood culture or another specimen with positive culture results, and Unexplained Fever (UF), defined as neutropenic fever with only febrile symptoms but did not met the CDI and MDI criteria.

The remaining serums that have been stored at $80^{\circ} \mathrm{C}$ were used for CRP and NETs examination. C-reactive protein levels were measured with the immunoturbidimetry method. Neutrophil extracellular traps levels were determined by measuring the levels of $\mathrm{Cit} \mathrm{H} 3$ using sandwich ELISA kit No. 501620 by Cayman, United States of America, and ChemWell 2910 analyzer.

Inclusion criteria of the study were patients aged 1 month to 18 years; malignancy patients who had a fever (total oral body temperature of $38.3^{\circ} \mathrm{C}$ or $38.0^{\circ} \mathrm{C}$ for $\geq 1$ hour continuously or at 2 measurements with a minimum distance of 12 hours); fever emerged in the first $\leq 72$ hours; patients who have not received antibiotic therapy before or have received antibiotic less than 72 hours; and patients who were willing to participate in the study and have given informed consent. The exclusion criteria were patients with a history of autoimmune disease; patients with a history of trauma and damaged or lysis blood samples. Statistical analysis was performed using SPSS ver. 20.0. Spearman correlation analysis was used in this study and the result was significant if $p$-value $<0.05$.

This study was approved by the Health Research Ethics Committee of the Faculty of Medicine, Sriwijaya University and Dr. Mohammad Hoesin Central General Hospital (number 508/ kepkrsmhfkunsri/2019).

\section{RESULTS AND DISCUSSION}

The subjects in this study were 18 patients consisting of 14 males (77.8\%) and 4 females (22.2\%). This study found a higher number of males compared to females in pediatric malignant patients with neutropenic fever. This result was consistent with the study by Nordal et al., which found a higher number of males (53\%) than females (47\%) who suffered malignancies with neutropenic fever. ${ }^{11}$ Study by Mohammed et al. with a sample of 135 malignant patients with neutropenic fever also found more than two thirds (68.9\%) of total patients were males. ${ }^{12}$

The mean age of pediatric malignancy patients in this study was $95.44 \pm 57.56$ months. Research by Sulviani et al. found that the mean age was $99 \pm 39$ months. ${ }^{13}$ Agnes et al. obtained the median age of malignant children with neutropenic fever was 56 (14-191) months. ${ }^{14}$ Neutropenic fever occurs and is affected by chemotherapy and socioeconomic status. $^{15}$

Based on the nutritional status, most malignant patients with neutropenic fever had good nutritional status. These results were similar to studies by Sulviani et al., which found that most malignant patients with neutropenia had good nutritional status, which was 39 (45\%) of 87 research subjects. ${ }^{13}$ Research by Agnes et al. found that malignant patients with neutropenia had good nutritional status more than another nutritional status, which was 24 (48\%) patients out of 50 patients. ${ }^{14}$ However, research by Jain et al. showed a contradictory result, that malignant patients with neutropenic fever were more common in patients with malnutrition. Differences in existed research results may be due to differences in the method and parameters of nutritional status assessment. Research by Jain et al. used a prospective cohort method and assessment of nutritional status using anthropometric, hematological, and biochemical parameters. 
Table 1. General characteristics and laboratory parameter of research subjects

\begin{tabular}{|c|c|c|}
\hline Characteristics & $\mathbf{N}$ & $\%$ \\
\hline Number of patients & 18 & $100 \%$ \\
\hline Age (month) (mean, SD) & $(95.44 \pm 57.56)$ & \\
\hline \multicolumn{3}{|l|}{ Gender $(n)$} \\
\hline Male & 14 & $77,8 \%$ \\
\hline Female & 4 & $22.2 \%$ \\
\hline \multicolumn{3}{|l|}{ Nutritional status (n) } \\
\hline Overweight & 1 & $5.6 \%$ \\
\hline Healthy weight & 13 & $72.2 \%$ \\
\hline Underweight & 3 & $16.7 \%$ \\
\hline Malnutrition & 1 & $5.6 \%$ \\
\hline \multicolumn{3}{|l|}{ Length of fever } \\
\hline$<24$ hours & 6 & $33.3 \%$ \\
\hline 24-36 hours & 2 & $11.1 \%$ \\
\hline 36-72 hours & 10 & $55.6 \%$ \\
\hline \multicolumn{3}{|l|}{ Diagnosis $(n)$} \\
\hline \multicolumn{3}{|l|}{ Hematologic malignancy } \\
\hline ALL & 5 & $27.8 \%$ \\
\hline AML & 8 & $44.4 \%$ \\
\hline \multicolumn{3}{|l|}{ Solid tumor } \\
\hline Osteosarcoma & 1 & $5,6 \%$ \\
\hline $\mathrm{NHL}$ & 2 & $11.1 \%$ \\
\hline Disgerminoma & 1 & $5.6 \%$ \\
\hline Lymphoma & 1 & $5.6 \%$ \\
\hline \multicolumn{3}{|l|}{ Infection } \\
\hline MDI & 6 & $33.3 \%$ \\
\hline CDI & - & $0 \%$ \\
\hline UF & 12 & $66.7 \%$ \\
\hline CRP levels (mg/L) & $170,17 \pm 121,52$ & \\
\hline NETs (CitH3) levels (ng/mL) & $0.77 \pm 0.39$ & \\
\hline
\end{tabular}

This study showed that there were 10 (55.6\%) patients with a length of fever $36-72$ hours, 6 (33.3\%) patients with a length of fever $<24$ hours, and 2 (11.1\%) patients with a length of fever of 24-36 hours. Hematologic malignancies were more common than solid tumors in this study. There were $13(72.2 \%)$ patients who suffered from hematologic malignancies, consisting of $5(27.8 \%)$ patients with Acute Lymphocytic Leukemia (ALL) and 8 (44.4\%) patients with Acute Myelocytic Leukemia (AML). These results were consistent with research by Nordal et al., which found that hematologic malignancies $(60 \%)$ were found in higher numbers than solid tumors (40\%). ${ }^{11}$ In a study by Nursyirwan et al. the highest neutropenic fever was found in hematologic malignancies such as ALL and AML (54\%). Most neutropenia is caused by hematologic malignancies. ${ }^{16}$ This is because of the basic disease process, the involvement of bone marrow, and the higher intensity of the required therapy. Chemotherapy in hematologic malignancies is longer and more aggressive than solid tumors. ${ }^{16}$

Based on the infection category, there were 6 (33.3\%) patients with MDI, there were no patients with CDI, and there were 12 (66.7\%) patients with UF. Research by Demirkaya et al. found $34 \%$ of patients with CDI, $34 \%$ of patients with UF, $6 \%$ of patients with MDI, and $10 \%$ of patients with sepsis. ${ }^{11}$ The study by William et al. found that MDI was the most common type of infection in neutropenic fever with a percentage of $63 \%$. Because the MDI category is more common within neutropenic fever patients compared with the CDI category, it can be concluded that neutropenic fever patients frequently do not show clinical symptoms (asymptomatic). Therefore, patients with neutropenic fever need to perform bacterial culture by using blood and urine samples to find the cause of infection. ${ }^{17,18}$ 
C-reactive protein mean level in this study was $170.17 \pm 121.52 \mathrm{mg} / \mathrm{L}$. A study by Demirkaya obtained a CRP levels of 64.4 (1.20-320.0) mg/L and 93.5 (4.0-306.0) $\mathrm{mg} / \mathrm{L}$ on the first day and the third day. ${ }^{1}$ Research by Shilpakar et al. obtained CRP level median of $97.94(0.18-378) \mathrm{mg} / \mathrm{L} .^{19}$ Based on the study by El-Maghraby, CRP levels of $61.8 \pm 83.8 \mathrm{mg} / \mathrm{L}$ was obtained in the unknown fever group, and $154.8 \pm 120.5 \mathrm{mg} / \mathrm{L}$ in the MDI and CDI groups. The study found that CRP levels were correlated with clinical and microbiological infections. C-reactive protein levels are the best predictor of bacteremia compared to IL-8 and MCP-1-a, which were found to have no association with bacteremia. Increased serum CRP $>90 \mathrm{mg} / \mathrm{L}$ correlates with positive culture results, especially in S.aureus and Gram-negative bacteria. $^{20}$

The NETs level in this study was $0.77 \mathrm{ng} / \mathrm{mL}$ with a standard deviation of $0.39 \mathrm{ng} / \mathrm{mL}$. This result was different from the results of research by Mauracher et al. the median value of Cit $\mathrm{H} 3$ was $26 \mathrm{ng} / \mathrm{mL}$ in patients with various diagnoses of solid tumors in adults. ${ }^{21}$ Research on cardiac arrest patients showed Cit H3 levels of $447(228-772) \mathrm{ng} / \mathrm{mL}$ and 386 (207-968) $\mathrm{ng} / \mathrm{mL}$ at 0 and 12 hours, respectively. ${ }^{22}$

Low cell-free DNA (cfDNA) levels in patients with neutropenic are caused by low leukocyte count. ${ }^{23}$ Decreased leukocyte count in malignant patients with neutropenic fever occurs due to the effects of chemotherapy. ${ }^{24}$ According to a study by Laukova et al. immature granulocytes were found in the blood of patients with acute myeloblastic leukemia remission. The granulocytes do not have the mature chromatin needed for the release of NETs, so neutrophils cannot perform the function of releasing NETs. ${ }^{25,26}$ Subjects in this study had low leukocyte and neutrophil counts due to the hematologic malignancies, the impact of chemotherapy, and most subjects were with the diagnosis of acute myeloblastic leukemia, which was suspected as the cause of low levels of $\mathrm{Cit} \mathrm{H} 3$.

This study showed that there was no significant correlation between CRP levels and NETs in malignancy patients with neutropenic fever $(r=0.228$, $p=0.362$ ). This study was different from the study by Bonnekoh et al. involving influenza patients. That study showed that the increase of NETosis increases CRP levels. Increased CRP levels in influenza patients correlate with plasma cfDNA levels. ${ }^{27}$ This is because circulating components of NETs are associated with systemic inflammatory injuries. Research on heart failure patients found a positive correlation between CRP levels and NETs $(p=0.033)$. C-reactive protein correlates with the neutrophil count in heart failure patients. Neutrophils increase proinflammatory activity through the release of NETs or so-called NETosis. ${ }^{28}$ Research by Diaz et al. found that there was a positive correlation between DNA and CRP $(p<0.01)$ in patients with Deep Vein Thrombosis (DVT), indicating that increasing CRP levels rises NETs levels. This correlation supports the association between DNA circulation, inflammation, and DVT. ${ }^{29}$

According to the research by Farkas et al., NETs are released into the circulation along with increased inflammatory markers (CRP and leukocytes) in thrombotic patients. ${ }^{30}$ Based on the results of research on patients with Renal Cell Carcinoma (RCC) by Wen et al. NETs formation is stimulated by increased CRP levels. ${ }^{31}$ Therefore, NETs are related to the inflammatory response. Renal cell carcinoma is associated with inflammatory reactions and elevated plasma CRP levels; therefore, it can be used as an indicator of inflammation and a predictor of poor prognosis in local RCC patients and RCC metastases. However, how CRP correlates with the survival of cancer patients remains difficult to understand. C-reactive protein levels have been reported to correlate with the production of interleukin-6 (IL-6), which mediates the ongoing inflammatory process. Thus, CRP parameters as indicators of non-specific inflammation can represent the microenvironment for the formation of NETs and activation of coagulation systems. ${ }^{31}$

Detection of CRP levels has been used in establishing the diagnosis of infection as well as monitoring the results of the treatment of infections in malignancy patients with neutropenic fever. A relatively strong and good response to inflammation makes CRP an ideal marker for inflammation and infection in malignancy patients with neutropenic fever. ${ }^{32}$ C-reactive protein directly interacts with blood mononuclear cells and plays a role in the inflammatory process. C-reactive protein can stimulate the release of IL-6, which further stimulates the mobilization of neutrophil progenitors in the bone marrow. This causes an increased number of neutrophils at the site of acute inflammation. The relationship between CRP and neutrophils directly represents the dependence between neutrophils, tissue macrophages, and blood monocytes. Interleukin- 6 increases the synthesis of CRP in hepatocytes, while CRP stimulates monocytes for the synthesis and release of IL- 6 and IL- 8 , which then stimulates neutrophils for migration and phagocytosis where inflammation occurs. ${ }^{33}$ Neutrophils are a type of leukocytes that play a role to encounter infection. Activation of neutrophils in 
malignancies and infections can cause the release of NETs. ${ }^{34}$ Neutrophil extracellular traps will bind and kill bacteria and fungi.

No significant correlation in this study might be due to several factors, such as a highly limited sample size, different characteristics of the sample population, diagnosis of various malignancy patients (dominant hematologic malignancy), as well as the length of fever, which indicated the time of infection in the study sample. Different length of fever can affect CRP levels and NETs. Compared to patients with a length of fever fewer than 24 hours, patients with a length of fever more than 24 hours showed a tendency of higher NETs levels in this study.

C-reactive protein levels have not increased significantly until 24-48 hours of inflammation. ${ }^{35}$ C-reactive protein increases rapidly after 6 hours and peaks around 48 hours of infection. ${ }^{33}$ According to Ketema, an increase in CRP levels is also directly related to the length of fever during hospitalization. ${ }^{32}$ Children with a longer fever have higher CRP levels compared to fever with a shorter duration. ${ }^{36}$ Research by Purhonen et al. found higher levels of cfDNA NETs one day after the onset of fever in hematologic malignancy patients with neutropenic fever. ${ }^{23}$ That condition might be the cause of no correlation found between CRP levels and NETs levels.

\section{CONCLUSION AND SUGGESTION}

The mean levels of CRP and NETs in malignant patients with neutropenic fever at Dr. Mohammad Hoesin Hospital, Palembang was $170.17 \pm 121.52$ $\mathrm{mg} / \mathrm{L}$ and $0.77 \pm 0.39 \mathrm{ng} / \mathrm{mL}$. There was no significant correlation between CRP levels and NETs in malignant patients with neutropenic fever. Further research related to other variables and inflammatory markers such as IL-6, IL-8, and platelets needs to be performed to determine the relationship of those markers.

\section{REFERENCES}

1. Demirkaya M, Tugcubc D, Akcaybc A, Aydogan G,

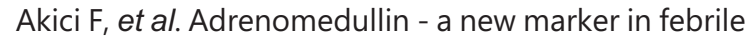
neutropenia: Comparison with CRP and procalcitonin. Pediatr Hematol Oncol,2015; 32(7): 1-8.

2. Yapici O, Gunseren F, Yapici H, Merdin A, Yaylali UU, Merdin FA. Evaluation of febrile neutropenic episodes in adult patients with solid tumors. Mol Clin Oncol, 2016; 4: 379-382.

3. Garley M, Jabłońska E, Dąbrowska D. NETs in cancer. Tumor Biol, 2016; 37(11): 14355-14361.

4. Hasler P, Aarau K, Giaglis S. Neutrophil extracellular traps in health and disease. Swiss Med Wkly. 2016;146:w14352 (October).

5. Brinkmann V, Zychlinsky A. Neutrophil extracellular traps: Is immunity the second function of chromatin?. J Cell Biol, 2012; 198(5): 773-783.

6. Hamaguchi S, Hirose T, Matsumoto N, Akeda Y, Irisawa $\mathrm{T}$, et al. Neutrophil extracellular traps in bronchial aspirates: A quantitative analysis. Eur Respir J, 2014; 43: $1709-1718$.

7. Kim JK, Hong CW, Park MJ, Song YR, Kim HJ, Kim SG. Increased neutrophil extracellular trap formation in uremia is associated with chronic inflammation and prevalent coronary artery disease. J Immunol Res. 2017; Article ID 8415179.

8. Zhu L, Liu L, Zhang Y, Pu L, Liu X, et al. High level of neutrophil extracellular traps correlates with poor prognosis of severe Influenza infection. J Infect Dis,2017; XX00: 1-10.

9. Soderberg $D$, Kurz T, Motamedi A, Hellmark T, Eriksson $P$, Segelmark $M$. Increased levels of neutrophil extracellular trap remnants in the circulation of patients with small vessel vasculitis, but an inverse correlation to anti-neutrophil cytoplasmic antibodies during remission. Rheumatology, 2015; 54: 2085-2094.

10. Nasution JM. Akurasi Interleukin-8 (IL-8) dalam membedakan infeksi bakteri dan non-bakteri pada pasien keganasan dengan demam neutropenia. Palembang, Universitas Sriwijaya, 2018. Tesis.

11. Nordal E, Stabell N, Stensvold E, Gammelsrud KW, Lund $B$, et al. Febrile neutropenia in children with cancer: A retrospective Norwegian multicentre study of clinical and microbiological outcome. Scan J Infect Dis, 2007; 1-7.

12. Mohammed HB, Yismaw MM, Fentie AM, Tadesse TA. Febrile neutropenia management in pediatric cancer patients at Ethiopian tertiary care teaching hospital. BMC Res Notes,2019; 12: 528.

13. Sulviani $R$, Idjradinata $P$, Raspati $H$. The risk factor for febrile neutropenia during chemotherapy in children with malignancy. Paediatr Indones, 2007; 47(2): 83-87.

14. Agnes $\mathrm{M}$, Widjajanto $\mathrm{PH}$, Damayanti W. Induction phase chemotherapy. Paediatr Indones, 2018; 58: 298-304

15. Puumala SE, Ross JA, Aplenc R. Epidemiology of childhood acute myeloid leukemia. Pediatr Blood Cancer, 2013; 60(5): 728-33.

16. Nursyirwan SR, Windiastuti E. Kejadian demam neutropenia pada anak dengan keganasan. Sari Pediatri, 2017; 19(4): 220-225.

17. Vathana N, Thitipolpun S, Buaboonnam J, Phuakpet K, Sanpakit K. Prevalence of pathogens in pediatric cancer patients with febrile neutropenia. Southeast Asian J Trop Med Public Health, 2017; 48(2) : 151-60.

18. William A, Purnamasari R, Iriani $Y$, Theodorus. Perbandingan efektivitas kombinasi Ceftazidime+Amikasin dan Ceftazidime sebagai antibiotik empiris demam neutropenia pada keganasan. Sari Pediatri, 2014; 16(4): 241-7.

19. Shilpakar R, Paudel BD, Neupane P, Shah A, Acharya B, 
et al. Procalcitonin and C-reactive protein asmarkers of bacteremia in patients with febrile neutropenia who receive chemotherapy for acute leukemian: A prospective study from Nepal. J Global Oncol, 2019; 1-6.

20. EL-Maghraby SM, Moneer MM, Ismail MM, Shalaby LM, EL-Mahallawy HA. The diagnostic value of C-reactive protein, interleukin-8, and monocyte chemotactic protein in risk stratification of febrile neutropenic children with hematologic malignancies. J Pediatr Hematol Oncol,2007; 29(3): 131-136.

21. Mauracher LM, Posch F, Martinod K, Grilz E, Daullary T, et al. Citrullinated histone $\mathrm{H} 3$, a biomarker of neutrophil extracellular trap formation, predicts the risk of venous thromboembolism in cancer patients. J Thromb Haemost, 2018; 16(3): 508-518.

22. Mauracher LM, Buchtele N, Schörgenhofer C, Weiser C, Herkner $\mathrm{H}$, et al. Increased citrullinated histone $\mathrm{H} 3$ levels in the early post-resuscitative period are associated with poor neurologic function in cardiac arrest survivors - a prospective observational study. J. Clin. Med, 2019; 8: 1568.

23. Purhonen $A K$, Juutilainen $A$, Vanska $M$, Lehtikangas $M$, Lakkisto $\mathrm{P}$, et al. Human plasma cell-free DNA as a predictor of infectious complications of neutropenic fever in hematological patients. Infect Dis,2015; 47(4): 255-259.

24. Fomenko Y, Kolesnikova Y, Beynikova Y, Muravlyova L, Sirota V, Bakirova R. Influence of combined therapy on generation of neutrophil extracellular traps in patients with cervical cancer. Open Access Maced J Med Sci, 2018; 25; 6(11): 2097-2100.

25. Lauková L, Konečná B. NETosis - Dr. Jekyll and Mr. Hyde in inflammation. J Appl Biomed,2018; 16(1): 1-9.

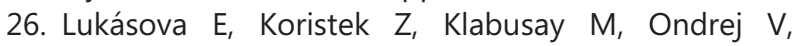
Grigoryev $S$, et al. Granulocyte maturation determines ability to release chromatin NETs and loss of DNA damage response; these properties are absent in immature AML granulocytes. Biochim Biophys Acta, 2013; 1833: 767-79.
27. Bonnekoh H, Scheffel J, Wu J, Hoffmann S, Maurer M, Krause K. Skin and systemic inflammation in Schnitzler's syndrome are associated with neutrophil extracellular trap formation. Front Immunol, 2019; 10: 546.

28. Vulesevic B, Lavoie SS, Neagoe PE, Dumas E, Rakel A, et al. CRP induces NETosis in heart failure patients with or without diabetes .Immuno Horizons, 2019; 3(8): 378-388.

29. Diaz JA, Fuchs TA, Jackson TO, Kremer Hovinga JA, Làmmle $B$, et al. Plasma DNA is elevated in patients with deep vein thrombosis. J Vasc Surg: Venous and Lym Dis, 2013; 1: 341-348.

30. Farkas ÁZ, Farkas VJ, Gubucz I, Szabo L, Balint K, et al. Neutrophil extracellular traps in thrombi retrieved during interventional treatment of ischemic arterial diseases. Thromb Res,2019; 175; 46-52.

31. Wen L, Guo L, Zhang W, Li Y, Jiang W, et al. Cooperation between the inflammation and coagulation systems promotes the survival of circulating tumor cells inrenal cell carcinoma patients. Front. Oncol,2019; 9: 504.

32. Ketema EB. Value of CRP as a marker of infection in cancer patients with febrile neutropenia: Review. Int. J Pharm SciRes, 2016; 7(6): 278-283.

33. Naskalski JW, Maziarz B, Kusnier-Cabala B, Dumnicka P, Panek J. Monocyte and neutrophil direct counts correlate with C-reactive protein plasma concentration in patients with acute pancreatitis. Cent Eur J Med, 2007; 2(1): 26-36.

34. Amulic B, Cazalet C, Hayes GL, Metzler KD, Zychlinsky A. Neutrophil function: From mechanisms to disease. Annu Rev Immunol, 2012; 30(1): 459-489.

35. Miedema KGE, de Bont ESJM, Elferink RFMO, van Vliet MJ, Nijhuis CSMO, et al. The diagnostic value of CRP , IL-8, PCT, and STREM-1 in the detection of bacterial infections in pediatric oncology patients with febrile neutropenia. Support. Care Cancer 2011; 19: 1593-1600.

36. Asturias EJ, Corral JE, Quezada J. Evaluation of six risk factors for the development of bacteremia in children with cancer and febrile neutropenia. CurrOncol, 2010; 17(2): 59-63. 